\title{
GENETIC INFORMATION, LIFE INSURANCE, AND SOCIAL JUSTICE ${ }^{1}$
}

\section{Introduction}

The aim of this paper is to discuss one of the ways in which advances in genetic technology and genetic knowledge threaten to generate a significant problem for our efforts to secure social justice, and to suggest a solution to that problem. The problem in question relates to the distribution of access to life insurance within a society with a high level of genetic information, and is part of a broader family of related problems concerning the relationship between individual risk and genetic information. ${ }^{2}$ Although the discussion of this paper proceeds in large part at a fairly abstract level, the problems posed by the prospect of ever-growing genetic information present a number of concrete public-policy dilemmas, with which courts and legislatures are currently grappling in many parts of the world. ${ }^{3}$

My discussion begins by laying out the legal, institutional, and medical background that frames the normative ethical and political problems with which I will primarily be concerned. I then lay out a trilemma, generated by the three available possible solutions to the problem, which demonstrates the available trade-offs that can be made between the various values of individual autonomy and self-direction, privacy, equality, non-discrimination, and choice-sensitivity. I then highlight the significance of life insurance as a "gateway social good," and, given this, I sketch the public-policy choices that would be mandated by the most ethically acceptable solution to this trilemma.

The discussion in this paper makes special reference to the current situation in the United Kingdom, but this is not to say that the difficulties being discussed are in any way peculiar to the U.K.; rather, questions concerning the normative dimensions of the regulation of genetic information are quite general, and the particular issues discussed in this paper will be salient in any free-market economy in which commercial life-insurance is widely used as a means of pooling individual risk. The particular focus on

"Genetic Information, Life Insurance, and Social Justice" by Martin O'Neill,

The Monist, vol. 89, no. 4, pp. 567-592. Copyright (C) 2006, THE MONIST, Peru, Illinois 61354. 
the U.K. is, therefore, to be understood simply as a way of rendering the issues under examination especially vivid, and to provide a context in which one can highlight the philosophical dimension of one particular ongoing public policy debate about insurance and genetics.

\section{Background, I: Life Insurance, Mutuality, and Solidarity}

In the U.K., as in most developed countries, life insurance is generally provided on a commercial basis by large insurance companies. The majority of life-insurance contracts (figures vary from estimates of around $90 \%$ up to $97 \%)^{4}$ are provided on "standard terms," whereby the only factors used to differentiate individuals into different risk groups are (i) age, (ii) sex, and (iii) smoking status. In general, life-insurance terms are cheaper the younger one is, and they are cheaper for women than they are for men, and for nonsmokers than for smokers. Other than that, individuals face broadly similar terms within the life-insurance market.

Life insurance is typically taken out in connection with two broad purposes: (i) in order to protect the payments on a loan, as in the case of mortgage loans, where uptake of such insurance is often made a condition on the loan being offered; and (ii) to provide a form of income replacement for other family members in case of premature death. Companies offering life insurance are entitled, under current arrangements, to ask for information relating to an individual's lifestyle, medical history, and family medical history. This information is sometimes used to set special terms for insurance underwriting: for example, when an individual has a dangerous hobby (such as parachuting or mountain climbing); a preexisting medical condition; or a family history of a particular ailment.

The system by which life insurance is provided in the U.K. involves the operation of a standard, voluntary mutual insurance market. Mutualistic insurance schemes are to be contrasted with solidaristic insurance schemes, such that insurance arrangements can be divided into two broad types. ${ }^{5}$ It will be useful at this point to characterize these two broad types of insurance regime:

\section{A. Mutuality, or Mutual Insurance:}

A mutual insurance market operates through the pooling of risk, with payment into the pool being in accordance with the best estimate of the 
level of risk brought to the pool. Typically, such schemes are private and contractual. The level of cover offered is often related to the amount of insurance purchased. Such schemes are usually voluntary; individuals therefore have a level of discretion over the amount of cover that they wish to purchase. The current life insurance market in the U.K. is a paradigm example of a mutual insurance market.

\section{B. Solidarity, or Solidaristic Insurance:}

In contrast to mutual insurance, the other broad category is that of "solidaristic insurance" (or, simply, "social insurance"). In this kind of insurance model, risks are pooled, and payment into the risk pool is in accordance with some agreed scheme (often ability to pay, or perhaps even strict equality of contribution), but is independent of the level of risk brought to the pool. Thus, the level of insurance cover is independent of the level of payment, and is generally associated with the level of individual need. Such schemes tend to be state run, and are typically comprehensive (i.e., they cover everybody) and compulsory. Given this, individuals tend not to have discretion over the level of cover that they will enjoy. A typical example of such a scheme is the operation of health insurance in the U.K. (as in Canada and most E.U. countries), with the National Health Service supplying a (roughly) standard level of cover to all citizens, funded through general taxation. ${ }^{6}$

Now, for our purposes, one important point to note is that a compulsory scheme of solidaristic insurance can operate even if the insurer and insuree have different levels of information about the individual's level of risk. Given that the price of the insurance is not related to the level of known risk brought to the pool, and that the level of cover is not chosen by the individual insuree, high-risk individuals cannot benefit from any extra information they may have about their risk level by "over-buying" insurance. Similarly, as such schemes are compulsory, low-risk individuals do not have the option of opting-out of the risk pool.

By contrast, systems of mutual insurance are only stable under conditions of informational symmetry. This need for information symmetry can be explained by virtue of an instability that mutual insurance markets undergo in the face of informational asymmetry. If a high-risk individual 
knows more abut her risk level than does her insurance company, then she can buy insurance at a price that does not reflect the real level of risk that she brings to the pool. Accordingly, on the assumption that such an individual, ceteris paribus, would desire to maximize the monetary return to her dependents, then, insofar as she acts in a way that is prudentially rational, she will tend to buy too much insurance too cheaply. This problem is known by actuaries as the problem of "Adverse Selection" (or, sometimes "Anti-Selection"), and may be understood as a particular species of "moral hazard."7 It is also worth noting here that there is a parallel (although much less discussed) hazard the other way around, in that insurers may have, but not disclose, risk-relevant information about the individuals that they insure. ${ }^{8}$ This troubling problem would bear further investigation, but falls outside the scope of this essay.

The existence of significant levels of adverse selection acts so as to drive up the liabilities faced by the risk pool, whilst effectively shrinking contributions to that pool. Following on from this, the only solution open to the insurance company, if they are to avoid the critical situation of insurance failure whereby the liability faced by the risk pool outstrips the size of that pool, is to drive up the per-unit cost of insurance cover. But in this case low-risk individuals who know of their own low risk level will typically find it prudentially rational to opt-out of the insurance pool, as the mutual insurance market will now fail to offer reasonable value for money (given that per-unit costs of cover are now skewed in such a way as to be excessively responsive to the needs of high-risk individuals). Assuming a plausible level of elasticity of demand for life insurance, prudentially rational action by high-risk and low-risk individuals will have the combined effect of driving up insurance prices to such a level that it is irrational for all but the most high-risk individuals to take out any insurance at all. In short, informational asymmetry leads to adverse selection, which leads to market failure.

Given the structural instability in mutual insurance markets that is generated by significant informational asymmetry, insurance contracts are unusual amongst commercial contracts in relying on principles of "utmost good faith," or "uberrima fides," rather than a weaker principle of "let the buyer beware" ("caveat emptor"). Insurance contracts are only legally enforceable if there is full disclosure of relevant information. So, whilst most commercial contracts require only a negative duty of non-misrepresentation in order to be legally binding, insurance contracts require a 
positive duty of disclosure. ${ }^{9}$ This explains, in part, why insurance companies are permitted to ask questions about lifestyle, medical history, and family medical history of those who are seeking insurance from them. This informational symmetry is thus well-entrenched as a central aspect of insurance contracts. ${ }^{10}$ We can thus specify a principle of informational symmetry, which characterizes a necessary feature of any ongoing, stable mutual insurance market.

\section{The Principle of Informational Symmetry:}

Mutual insurance markets are stable only under conditions where there is no significant divergence in the level of risk-relevant information available to the insurer and insuree.

As things stand, of course, we tend to have fairly low levels of information about our own life-expectancy, or our risk levels with regard to a range of possible health outcomes. Thus, the informational background against which life-insurance contracts are formed is a fairly sparse one. Low levels of information like this make informational symmetry very easy to achieve: insurance companies do not have enough information to make reliable, fine-grained judgments about how long any individual is going to live, but neither is the individual in question able to make such judgments. What information we do have (given via family history, individual medical history, etc.) is also available to insurance companies. So, the level of informational symmetry needed for the integrity of the market is retained, and the mutual insurance market in life insurance remains stable.

Thus, as things stand, with our sparse background of risk-relevant information, we have the conditions for a stable mutual insurance market. But, crucially, our level of knowledge of risk-relevant genetic information has recently begun to rise, and shows every sign of rising even more rapidly in the future. Having characterized the current legal and institutional background with relation to the nature of life insurance, we should now turn to a brief examination of the relevant background in terms of recent biomedical advances and gains in genetic information.

\section{Background II: Genetic Information and Genetic Testing}

Very many medical conditions have a genetic component, insofar as an individual's risk of developing that condition is, in part, a function of her genetic make-up. As genetic technology has advanced, it has become 
increasingly possible to identify and evaluate the genetic component of an individual's risk of developing a number of diseases. Thus, John Bell, the Regius Professor of Clinical Medicine at Oxford University, tells us:

This approach has been applied systematically to (i) a wide range of cancers; (ii) autoimmune disorders such as juvenile diabetes, rheumatoid arthritis and inflammatory bowel disease; (iii) degenerative diseases and diseases of aging such as osteoarthritis and Alzheimer's disease; (iv) metabolic diseases such as Type II diabetes and obesity; and (v) cardiovascular diseases. This approach has led to the discovery of a substantial number of genetic localizations of disease genes throughout the human genome, and in some cases the identification of the disease genes themselves, and the DNA variants that contribute to disease susceptibility. ${ }^{11}$

At the current state of scientific understanding, doctors have a very good understanding of the genetic determinants of a number of diseases. Many of these diseases are of early onset, or generate a condition that is present from birth, such as Duchenne muscular dystrophy or Down's Syndrome. Others, such as haemophilia, emerge by adolescence. It is important to note that cases such as these are not relevant with regard to questions of the relationship between genetic information and access to life insurance. In such cases, the information is either irrelevant (due to the terrible misfortune of an early death at a stage in life before an individual would typically seek life insurance), or else has emerged clearly before the individual reaches adulthood, through the emergence of visible symptoms (and hence [i] the genetic information does not provide new risk-relevant information to the insurer or insuree, and [ii] the existence of the condition would already be disclosable information under current insurance arrangements). 12

There are a number of cases, though, of so-called "late onset autosomal-dominant disorders," which are diseases that affect people in adulthood, and for which a genetic test can be given before any symptoms of the disease have shown themselves. This class of disorders includes progressive neurodegenerative diseases, such as Huntington's Disease, which is associated with the so-called HD gene, cardiovascular disorders such as Marfan Syndrome, which carries a risk of sudden death in later life, and several forms of familial cancers, such as the form of breast cancer associated with the BRCA1 and BRCA2 genes, and certain varieties of colon cancer. ${ }^{13}$ Testing for late-onset conditions of these sorts provides individ- 
uals with significant new information about their risk levels, which they could not have obtained other than through genetic testing, and which can be accessed in advance of any symptoms presenting themselves.

Besides these autosomal-dominant disorders, there is also an important class of "multifactorial" conditions, for which an individual's genetic constitution has a significant influence on his or her overall risk levels. Most of the set of diseases that will kill the majority of us-cardiovascular disease leading to heart attack and stroke; the various kinds of multifactorial cancers; as well as most forms of senile dementia-are of this "multifactorial" type, whereby individual susceptibility is determined by the complex interplay of a range of genetic, lifestyle, and environmental risk factors. As the genetic component of the epidemiology of such conditions becomes better understood, it is extremely likely that levels of information as to individual risk will continue to rise. 14

Thus, as things stand, the genetic basis for many autosomal-dominant diseases is sufficiently well-understood that a simple genetic test can provide substantial information as to an individual's level of risk with respect to that disease. And, whilst genetic testing with regard to the more complex conditions mentioned above is in its infancy, we are nevertheless at the early stages of development of a powerful new science of genetic risk-determination.

\section{Privacy, Market Failure, and the Regulatory Regime}

Clearly, advances in genetic technology carry enormous potential medical benefits. Knowledge of one's genetic risk with regard to a variety of conditions can, in many cases, allow one to shape one's life so as either to reduce that risk (through changes in behaviour, or early medical intervention), or at least to come to terms with what might lie ahead. But as well as carrying great promise, with the potential to transform our understanding of our future health from a mysterious realm of uncertainty to one of more clearly definable and actionable risks, these advances also threaten to destabilize our current social arrangements, and to usher in new forms of discrimination and new sources of inequality. 15

Because of the importance, usefulness, and sensitivity of genetic information, we reasonably tend to think that information given by genetic tests should be available to individuals, and that those individuals should generally be permitted to keep such information private. People have a le- 
gitimate interest both in having access to this kind of information themselves, and in preventing others from accessing the information. But privacy over this kind of genetic information, when relevant to risk levels, would lead to the kind of informational asymmetries that would violate the Principle of Informational Symmetry, thereby threatening the stability of the mutual life-insurance market. On the other hand, if such information is not allowed to be kept private, then individuals will be deterred from undergoing genetic tests, given the worry that they will have to reveal any adverse results to their insurance company when entering into an insurance contract.

These difficulties generate a significant ethical and political problem to which a solution must be found. The question at hand is this: Should we restrict all access to genetic information of this type, or should we instead sacrifice the individual's right to privacy; should we allow the violation of the Principle of Informational Symmetry (and hence the possible collapse of the mutual-insurance market), or might we be able to find some other principled policy solution?

When we turn to the politics of this issue, it is striking that the current U.K. policy solution is an unstable stop-gap, which will need long-term replacement by a more principled and stable solution. At the moment, there is a moratorium on insurers being entitled to access the results of genetic tests for life insurance amounts up to $£ 500 \mathrm{k}$, and for criticalillness coverage up to $£ 300 \mathrm{k}$. The only exception is for a test for the HD gene, which leads to the development of Huntington's Disease. The U.K. Department of Health's Genetics and Insurance Committee (GAIC) has approved the use of this test, on the grounds that it is sufficiently reliable and accurate to be used in setting life insurance terms. As this suggests, GAIC's concerns therefore seem primarily to be connected with the prevention of inaccurate or unreliable tests being used in life-insurance underwriting, rather than with considering the underlying normative question of whether individuals should have a principled entitlement to keep such information private whilst still being able to have access to life insurance. Moreover, there is nothing in the current moratorium to stop individuals from voluntarily disclosing the results of genetic tests, in exchange for the insurance company offering them more attractive terms than they would otherwise be inclined to offer. This moratorium runs up to 2011, with a review due in 2008. Beyond this temporary moratorium, policy is undecided in the long-term. As one might expect, elements in the insurance 
industry are campaigning for these regulations to be relaxed, so that genetic information can be used in insurance underwriting in the same way that other forms of information are already used; on the other hand, many patient-advocacy groups are campaigning for the current moratorium to be extended or strengthened. What all sides agree upon is that the current solution is merely a provisional one, and that a more permanent solution to the problem must be found. ${ }^{16}$

\section{Deeper Problems: Genetic Discrimination,} Mutual Insurance Markets, and Increasing Genetic Information

If there is to be a functioning mutual-insurance market, with the Principle of Informational Symmetry being upheld, then it must be the case that, if individuals are allowed access to their genetic information, then that same information must also be made accessible to insurance companies. In the long run, this will lead to the division of risk pools in accordance with people's levels of genetic risk, insofar as that information is likely to be actuarially significant (which it certainly would be with regard to, for example, Huntington's Chorea or BRCA cancers).

Now, what is surely unarguable is that this amounts to genetic discrimination with regard to access to life insurance. This is not to say that it must therefore be impermissible - but it does mean that, if we are to allow a high-information, stable mutual-insurance market, then it seems that we have to be able to countenance practices that are discriminatory across individuals on the basis of differences in their unchosen genetic endowment (or, to use a phrase of Rawls's, according to their place in "the natural lottery"). ${ }^{17}$ Now, there seems at least to be a strong prima facie presumption that discrimination with regard to such a feature of individuals is illegitimate. ${ }^{18} \mathrm{By}$ and large, discrimination on grounds that relate to a feature that is unchosen and which constitutes an aspect of an individual's identity is considered illegitimate. In this respect, "genetic discrimination" may seem impermissible in the same way, and for much the same reasons, as discrimination on grounds of race or ethnic origin is held to be impermissible. Moreover, this would be discrimination against a group which, because of its risk of developing serious medical conditions, would already be worse off (ceteris paribus) than most others.

It is worth mentioning that there are interesting issues here with regard to age-discrimination and sex-discrimination, both of which are 
generally considered to be legitimate as far as life insurance is concerned. Age-discrimination seems legitimate given that it seems not to involve treating individuals differently from one another, but simply to involve treating all individuals in a way that is sensitive to their current life-stage. Sex-discrimination in life insurance may seem permissible on the basis of the manifestly contingent fact that it typically favours women over men (given that women have lower morbidity rates, they represent [ceteris paribus] a smaller risk for the insurance company). Given that such a large proportion of our socioeconomic arrangements favour men over women, it may not seem too egregious if the life-insurance market operates as a mildly redistributive mechanism in women's favour. ${ }^{19} \mathrm{Dis}-$ crimination on the basis of smoking-status also seems to be legitimate, insofar as smoking is a voluntary activity which is within the discretion of the insuree, although this is not to say that such discrimination is clearly wholly unproblematic. ${ }^{20}$

But, even if discrimination on age, sex, and smoking-status is considered permissible, it seems much more difficult to make the case for the permissibility of discrimination on grounds of genetic profile. It seems that there would need to be a strong reason for us to favour a policy solution which led to "genetic discrimination," given the prima facie impermissibility of discrimination of this broad type; although perhaps there would be good enough reason for us to do so if this choice represented the lesser of a number of evils. In the following section I will turn to the structure of the choice situation we face with regard to public policy on this issue, and present the "trilemma of genetics and life insurance."

\section{The Trilemma of Genetics and Life Insurance:}

\section{Non-Discrimination, Genetic Information, and Choice-Sensitivity}

We have seen that any solution involving informational asymmetry in a mutualistic insurance market is impossible, as it generates a structural instability in that market. Given that we cannot square the circle of having a stable mutual insurance market with protected, private genetic information and no genetic discrimination, as a matter of policy we have three broad options open to us. This generates a trilemma, where choosing any of the three horns carries its own normative benefits and costs. A principled solution to this public policy puzzle must take a clear and reasoned choice of one of these three options. 


\section{Option 1: High-Information Mutuality:}

This involves allowing individuals and their insurers to have access to risk-relevant genetic information. This option preserves important aspects of individuals' interests in accessing genetic information, albeit not on terms of privacy. It also preserves choice-sensitivity with respect to selection of insurance policy, as such policies are still chosen voluntarily, with different options available in a free market. However, the price paid in choosing this option is to allow genetic discrimination in access to life insurance, such that an already disadvantaged group either has to pay much more in order to access life insurance, or else is denied that access altogether.

\section{Option 2: Enforced Low-Information Mutuality:}

This option involves a restrictive policy whereby the state denies everyone access to the results of genetic tests. That is to say, certain genetic tests would simply have to be made legally impermissible, such that neither individuals nor their insurers could have access to risk-relevant genetic information. This option preserves the broadly non-discriminatory nature of the insurance market, as it precludes the possibility of the dissemination of information that would be used in making the relevant genetic discriminations between individuals. This option also preserves choice-sensitivity regarding selection of insurance policies, as a free market structure could be maintained for insurance provision. What is sacrificed in this option are individuals' interests in accessing their own genetic information, and in being able to use that information in making well-informed choices about their own behaviour, lifestyle, and future life-plans.

\section{Option 3: High-Information Solidarity:}

This option involves the radical step of abandoning the mutual lifeinsurance market, in favour of a replacement solidaristic mechanism. This approach allows us to preserve individuals' interests in accessing genetic information on terms of privacy (with the gains for individual rational self-determination that this involves), and it also avoids any form of genetic discrimination. This option involves a "one-sided" form of High Information, in that individuals would have full access to information about their own genetic profile, which they need not share with insurers. The cost of adopting this solution is that one must sacrifice the choice-sen- 
sitivity over the terms of life insurance arrangements that can be achieved through a voluntary free-market in mutual insurance.

In short, Option 1 gives us choice-sensitivity over policies, as well as individual access to genetic information (albeit not on terms of privacy), but does so at the cost of allowing genetic discrimination. Option 2 gives us choice-sensitivity over policies and avoids genetic discrimination, but does so at the cost of depriving individuals of valuable genetic information, at a significant cost to both their well-being and their capacity for autonomous agency. Option 3 avoids genetic discrimination, and allows individuals to have full access to useful genetic information, here on terms of full privacy. But pursuing the third option also involves the potential disadvantages of moving from a flexible, choice-sensitive free-market solution to a universal, compulsory, centralized solution.

\section{The Case Against High-Information Mutuality:}

Non-Ideal Theory, and the Social and Economic Role of Life Insurance

One important question that stands behind our discussion concerns the social and political significance of life insurance. In short, is access to life insurance really all that important? If it was just an ordinary commercial instrument, or a luxury item, then it would not be so awful to have, as in Option 1 of the trilemma, genetic discrimination in access to life insurance. If life insurance were of such limited importance, then High-Information Mutuality (i.e., Option 1) might be acceptable. But if access to life insurance could be shown to be of considerable social and economic significance, then it would appear that the High-Information Mutuality option, with its allowance of genetic discrimination with regard to access to life insurance, would be much more likely to be ruled out as a possible solution to our trilemma.

In fact, life insurance, rather than being a pleasant luxury financial item, is best seen as (what I shall call) a gateway social good. Life insurance facilitates certain forms of economic and social activity, such as the kind of entrepreneurial activity in which individuals can engage if they have access to large and reasonably-priced bank loans; it allows access to the housing market; it facilitates stable family life; and it provides for longterm planning of a kind that would be impossible under uncontrolled levels of risk. Thus, life insurance is a social good which is best understood through 
its relation to a broader set of other social goods. It has an importance which is not intrinsic, but which is given by the way in which it functions as a gateway to this broader set of goods. Significantly, among the broad set of goods to which life insurance provides a "gateway" are some goods of tremendous importance. Access to a full range of financial products, including the mortgage needed to buy a house, is a very basic precondition of full economic citizenship in a society such as ours. Moreover, the opportunity to create and sustain a stable family life seems also to be a very basic and fundamental social entitlement. ${ }^{21}$ Perhaps most significantly of all, access to life insurance is an important pre-requisite for certain kinds of long-term planning-with regard to both economic and family lifewhich are absolutely central aspects of living a full and successful human life. In both the private and public spheres of individual activity, life insurance can serve as a gateway to robust diachronic agency of a kind that would be impossible to achieve under unmanaged levels of risk.

This "gateway" feature of life insurance may be quite general in its application (given its role in facilitating long-run planning of certain kinds) but it certainly at least obtains under any basic structure of the same broad type as the one we currently have. 22 That is, for any basic socioeconomic structure in which commercial life insurance is the dominant mechanism through which a family can secure a replacement income in the tragic event of the death of a breadwinner, and in which there is a common requirement that individuals taking out large loans have their lives insured, life insurance will be a gateway social good of great significance. And in any structure where life insurance does function as a gateway social good, protection of non-discriminatory access to that good will be of special importance.

Now, this leaves open the possibility that, in a more fully egalitarian society, access to life insurance would be of no great significance.Perhaps a fully egalitarian society would have unsecured loans for entrepreneurial economic activity; or perhaps such a society would have a social-welfare system that was sufficiently robust so as to make the income-replacement function of life insurance far less crucial than it is in societies like ours. Under such conditions, access to life insurance would be less significant, as life insurance would plausibly lack its "gateway" property.

In light of this, it is worth bearing in mind the methodological distinction between ideal and non-ideal theory. It is not the argument of this paper that, as a matter of ideal theory, social justice can only be secured in 
a basic structure in which broad access to life insurance on non-discriminatory terms is protected. For a truly just society might be such as to provide only a very marginal role for life-insurance arrangements. For present purposes, then, I want to remain neutral on this matter of ideal theory. Instead, the argument of this paper is an argument in non-ideal theory: specifically that, given the functions of life insurance within a basic structure like ours, securing access to life insurance on non-discriminatory grounds for all citizens is a goal of tremendous importance from the standpoint of social justice. The non-ideal theoretical question is an important one to address, given that, in terms of public policy, we are where we are. If political philosophy is to be of any use in clarifying the structure of the public policy choices open to us, it must address the problem as it presents itself here and now.

So, the claim that I want to defend here is that genetic discrimination with regard to a significant gateway social good of this kind is unacceptable if we are concerned with securing social justice. At the very least, such discrimination would undermine fair equality of opportunity, as it would structure life-chances in a way that was excessively determined by unchosen aspects of individuals' genetic endowments, and which would be quite irrelevant to matters of individual effort or choice. ${ }^{23}$ Moreover, insofar as some genetically unlucky individuals might find themselves not just having to pay more for their life insurance (and hence for the possibility of making use of life insurance's "gateway" function), but actually being wholly excluded from access to life insurance, this form of genetic discrimination could lead not only to a violation of fair equality of opportunity, but also to discriminatory social exclusion. Under such conditions of social exclusion, individuals could find themselves without any prospect of participating in the central features of socioeconomic life, or of sharing in the benefits of economic growth and cooperation. We would thus have the realisation of common fears of the creation of a genetic underclass.

In short, a plausible commitment to social inclusion and to broad equality of opportunity precludes genetic discrimination with regard to access to a gateway social good. Life insurance is a good of this kind, therefore it would be impermissible, insofar as we might wish to advance or secure social justice, to take Option 1 of our trilemma. Options 2 and 3 remain as the possible alternative choices, and we shall now consider them in turn. 


\section{The Case Against Enforced Low-Information Mutuality, and the Contingent Quasi-Fairness of "Natural" Low-Information Mutual Insurance Markets}

There are two ways in which we might find ourselves in conditions of low-information with regard to the market in life insurance. The first is the condition that has traditionally obtained, whereby we simply do not have very much information, because biomedical knowledge simply has not progressed sufficiently far in determining the genetic basis of medical risk. Let us call this situation a situation of "Natural" Low Information. This can be contrasted with the situation contemplated in Option 2, whereby there might be a deliberately imposed restriction in access to genetic information-for example, by banning certain kinds of genetic test. We can call this "Enforced" Low Information. One might want to argue in favour of an enforcement of low information if one thought that knowing too much about one's risk levels would simply be too disturbing or traumatic, or if one believed that human lives are best lived under the open blue skies of uncertainty, rather than in the potentially paralyzing shadow of known, quantifiable risk.

But before considering the desirability of enforced low-information mutuality, it is worth pointing out that, at least under conditions of "Natural" Low Information, mutual insurance markets can be (roughly) fair, in the sense of supporting rather than undermining social justice. To illustrate this point, let us consider the Parable of Bill and Ben.

\section{The Parable of Bill and Ben:}

Consider the case of a simple mutual insurance market, composed of two insurance buyers, whom we'll christen Bill and Ben. Bill and Ben are, let us suppose, very similar in their ambitions and outlook, their environment, choices, risk-aversion, and lifestyles. They were born on the same day, are both men, and both non-smokers. They diverge, for our purposes, only in the following respects:

(1) Bill is genetically unlucky, and will suffer from a late-onset familial colon cancer, to which he is genetically highly disposed. Ben, on the other hand, is genetically very lucky, and has no identifiable genetically-based disease-propsensities. 
(2) Bill dies at 54, whereas Ben lives to the ripe old age of 93.

If neither Bill nor Ben know the genetic information affecting their life-expectancy and disease-propensities, then, ceteris paribus, it will be rational for them to purchase the same amounts of life-insurance cover from a mutual insurance company. So, under these condition, Ben ends up subsidizing the sizeable insurance payout which is made to Bill's family when he dies prematurely. Although Bill's family are tremendously unfortunate in being deprived of their husband and father at such a young age, the cash transfer from the very fortunate Ben allows them to pay off their mortgage and face their future from a position of economic security.

However, if the information on genetic risk had been available to both Bill and Ben, then things would have turned out very differently. Ben, knowing the likelihood that he would live until well past retirement age, has much less reason to purchase life insurance, ceteris paribus, than does Bill. Hence, Ben purchases only a very small amount of life cover (as, let us suppose, he is now concerned, only with the risk of accidental death), and he is therefore no longer subsidizing the insurance payout to Bill's family. Bill now finds the cost of life insurance has risen, because of the drop in demand. He cannot afford insurance, in which case Bill finds it impossible to get a mortgage, and his family are thrown into economic uncertainty. When Bill dies young, his family are thrown into economic disarray, and find that their grief has been compounded by the unwelcome arrival of economic hardship.

What our parable shows is that, under conditions of low information, a mutual life insurance market acts as a de facto redistributive mechanism from the fortunate to the unfortunate, as well as being a mechanism for pooling risk. However, this is simply a contingent fact about the operation of the market, rather than a deliberate result of policy. Moreover, this de facto redistribution is (i) very rough (given that information on family history, individual medical history, and so on, is available to insurers and can be used to divide the risk pool) and (ii) unstable in the face of rising information. At root, redistribution from the fortunate to the unfortunate is an essential feature of the pursuit of social justice, but conditions of rising genetic information mean that this will no longer be a welcome side-effect which can obtain purely by accident. If such redistribution is 
to be retained under conditions of rising genetic information, then it has to be attained deliberately and as a matter of conscious political choice, and cannot come as an unintended consequence, as it does for Bill and Ben.

So: might a plausible way forward be to return to conditions of lowinformation, through a deliberate policy of information restriction? This is unlikely. For such a policy (choosing Option 2 of our trilemma) has enormous ethical costs, which surely outweigh the gain in (approximate) social justice which low-information insurance markets can bring. What is lost, in pursuing Option 2, is the valuable access that individuals would otherwise have to significant information about their own risk levels. If we return to Bill and Ben, it is clear that it would be of massive benefit to Bill if he had been able to have access to information about his own genetic predisposition to develop cancer. This information might have been vital for Bill in coming to a decision to change his diet or lifestyle, or to monitor his health more carefully. Even if there is no action that Bill could have taken to avoid his unfortunate fate, he might nevertheless have wanted to come to terms with his future sooner than he was otherwise able, or to make different decisions about whether and when to have a family. (He might, for example, have had his children younger if he knew what the future held.) Likewise, he might have adjusted his economic choices in significant ways if he knew what risks the future would bring. Now, perhaps Bill is one of those individuals who thinks that it is better to live a human life under uncertainty, rather than under the dead hand of quantified risk. But, if that were the case, it could always be open to Bill to refuse to undergo the relevant genetic tests. ${ }^{24}$ One need not make the revelation of risk-relevant genetic information to individuals compulsory, but in at least giving Bill the choice over whether to seek out this information, one is giving him a choice of tremendous value.

As this extension of our parable shows, individuals have a particularly strong interest in having access to risk-relevant genetic information. Such information has the capacity to be tremendously liberating, as well as allowing individuals to make well-informed decisions which have the capacity to extend their lives. Providing people with information of this kind has the prospect of leading to longer and less painful lives, and hence is surely to be welcomed insofar as we take an interest in the promotion of individual well-being; moreover, and probably more importantly, the provision of such information will transform individuals' opportunities to 
plan and shape their lives, maximizing their capacity for autonomous selfdirection within the constraints of their genetic endowment. Given this, and notwithstanding the ways in which low-information mutual insurance can provide a simulacrum of social justice, the vast balance of the relevant normative considerations should lead us to reject Option 2 of our trilemma.

\section{Solving the Trilemma-The Case for Solidaristic Life Insurance}

The two foregoing sections have eliminated Options 1 and 2 from our enquiry. Both carry too high a cost for them to be plausible solutions to the problem of regulating access to life insurance in the face of rising genetic information. This leaves us with Option 3-the abandonment of a mutual life insurance market in favour of an alternative solidaristic mechanism (which, as a matter of policy, could be achieved either by making the direct provision of life insurance the job of the state, or through a regime of very tight regulation of the private insurance companies). But Option 3 is not costless. What is sacrificed in taking this way out of our trilemma is individual choice-sensitivity over the content of insurance policies, of a kind that we could only retain given a free-market insurance mechanism.

I want nevertheless to suggest that taking Option 3 is a more acceptable solution than either eschewing social justice through allowing genetic discrimination over an essential gateway social good (Option 1), or by following the path of enforced genetic ignorance, and thereby denying individuals access to critically important and autonomy-facilitating information (Option 2).

The choice of Option 3 can be defended in two different ways. First, we can acknowledge the costs associated with a loss of choice-sensitivity, but argue that these costs are modest when compared with those associated with the other available options. That is to say, we can simply appeal to the relative weights of the three kinds of costs associated with choosing each of the three options. It is true that the loss of a certain degree of choice-sensitivity over selection of insurance policy is involved in accepting Option 3, but the loss here is surely marginal when compared with the much more substantial loss of individual autonomy associated with Option 2. Moreover, given that the value of life insurance is closely related to its gateway function, rather than being intrinsic, the loss to any individual in being subject to a limitation in choice over the precise structure of her life insurance contract (as in Option 3 ) is of very limited signifi- 
cance so long as that individual nevertheless has access to the broad set of important social goods to which life insurance functions as a gateway (and from which certain genetically unlucky individuals could be excluded under Option 1). Thus, the gains associated with providing universal access, on non-discriminatory terms, to those social goods that are opened up by access to life insurance are sufficiently substantial to outweigh the costs associated with the restriction of certain commercial freedoms required by Option 3. The core of the case here is that the gains with regard to individual autonomy and social justice associated with Option 3 are simply of an order of magnitude greater than the marginal losses to contractual freedom which this solution to our problem unavoidably involves.

The second way of defending Option 3 questions whether the costs associated with making that policy choice are as high as they initially appear. What should be remembered here is that the adoption of a solidaristic lifeinsurance regime is consistent with (and, indeed, would require) democratic co-deliberation with regard to the shape of the life-insurance policies provided to citizens, thus providing an important scope for choice-sensitivity through mechanisms other than individual market decisions. Structuring a regime of socialized life insurance would be no easy task: deep normative problems would arise with regard to decisions regarding what an appropriate level of cover might be, and on what factors the expected levels of contribution or entitlement should depend. ${ }^{25}$ But solutions to these problems can be sought through a democratic politics which aims to be sensitive to the preferences and attitudes of citizens. This is not to suggest that a substantive problem can be overcome by a purely procedural solution, but it is to say that there are ways of enshrining choice-sensitivity other than through leaving arrangements to market solutions. Indeed, it is an instructive contrast to compare the genuine choice that citizens would enjoy collectively under conditions where they deliberated democratically over the structure of the socialized life-insurance regime, as opposed to the purely chimerical choice faced by a genetically ill-favoured individual when spurned by commercial insurance companies under the conditions that would prevail in a high-information mutual-insurance market (i.e., under Option 1).

On the one hand, then, to the extend that choice-sensitivity is lost in adopting a solidaristic approach to life insurance, this loss is small in comparison with the costs of the alternative policy options. And, on the other hand, it is questionable how much choice-sensitivity is really lost, given 
that solidaristic insurance schemes could be responsive to choices made through collective deliberation. Either way, the balance of reasons points us decisively towards the adoption of Option 3, and the move towards High-Information Solidarity.

\section{Coda-The Possibility of Broad Overlapping Consensus: or, Why This Problem May Be Theoretically Simple (Though Practically Complex)}

In conclusion, I want to suggest that, although the adoption of Option 3 may appear to be a bold and radical solution to our problem, it is a solution on which we should expect broad convergence from any plausible account of the demands of social justice. This can be illustrated if we consider the issues on which theories of justice actually diverge, and what these theories have in common. For example, many disputes among theories of distributive justice involve thinking about the degree to which choices made by individual agents ought to affect their economic prospects. ${ }^{26}$ But genetic endowment is not a matter of individual choice, and is unrelated to individual effort. One's genetic makeup is entirely outside of one's own control. As genetic endowment is itself choice-insensitive, there is no scope for disagreement here over issues regarding responsibility, choice, or desert. Similarly, theories of justice also disagree about the degree to which we should aim for outcome equality, as against economic sufficiency, or giving priority to the worst off, or some other distributive goal. ${ }^{27}$ But, if life insurance is a gateway social good, such that providing access to it is important for providing basic economic opportunities, for securing basic rights, and for avoiding social exclusion, then all of these different sorts of theories should agree that it is an important matter of justice to ensure access to life insurance. In other words, if life insurance is a gateway social good, as this paper argues, then preserving non-discrimination in access to it should be a goal of strict-outcome egalitarians, advocates of equality-of-opportunity, prioritarians, proponents of democratic equality, and advocates of any other plausible account of the demands of justice.

So, to borrow a phrase of Rawls's, it seems that we can expect there to be a broad "overlapping consensus" on the importance, from the standpoint of social justice, of a move towards universal, solidaristic provision of access to life insurance. ${ }^{28}$ That such a broad consensus should be possible to achieve is further evident if we consider the widespread agreement that 
exists regarding the importance of the basic normative principles-of privacy, self-determination, non-discrimination, and equality of opportunity - of which the argument in this paper makes use. None of this is to deny that there are deep and awkward questions of institutional design and political mobilisation with regard to the move towards High Information Solidarity, but it is to suggest that this move is ethically unavoidable if we are to pursue a concern for social justice into the coming world of high and rising genetic information.

\section{St John's College}

Cambridge

Martin O'Neill

\section{NOTES}

1. For helpful comments on earlier versions of this paper, and for useful discussion of the issues that it raises, I am grateful to Brian Barry, Paul Bou-Habib, James Robert Brown, Andrew Clark, Axel Gosseries, Joe Guinan, Alon Harel, Mark Henderson, Mary Leng, Tim Lewens, Martin Mclvor, David Oderberg, Serena Olsaretti, Onora O'Neill, Shepley Orr, Derek Parfit, Avia Pasternak, Tom Porter, Andrea Sangiovanni, Margaret Schabas, Andrew Williams, and Jonathan Wolff. I am grateful to audiences at the Peter Wall Institute for Advanced Studies at the University of British Columbia, at the Annual Philosophy of Science Conference at the Inter-University Centre in Dubrovnik, and at the Sixth "Priority in Practice" Conference, at the School of Public Policy at University College, London.

2. One interestingly related set of problems concern access to health insurance under conditions of rising genetic information. For countries where healthcare is provided through a private market in health insurance, these problems are perhaps more pressing than the problems discussed in this paper. But the issues relating to access to life insurance are more general in scope, as they affect countries with systems of socialized medicine (such as Canada and the E.U. countries), as well as countries such as the United States, where both health-insurance and life-insurance are provided through market mechanisms. On the problems for health insurance raised by rising genetic information, see, for example Hudson et al., (1995); O'Neill (1997), (1998); Knoppers (1999); Burley (1999); Dworkin (2000), ch. 8; Buchanan, Brock, Daniels and Wikler (2000), ch. 8; Sorell, (2002); Radetzki, Radetzhi and Juth (2003); and Daniels (2004). Also of relevance is the Department of Health (2003), $\S 1.5$, which claims, strikingly, that "as our understanding of genetics advances, the case for private health insurance as an alternative to our universal tax financed NHS diminishes."

3. Among recent developments are the 2005 U.S. "Genetic Information Non-Discrimination Act" (information on which is available on the website of the U.S. National Human Genome Research Institute, at http://www.genome.gov ). See, also, the development of 
general principles contained in both the 1997 uNESCO Universal Declaration on the Human Genome and Human Rights (available from http://www.unesco.org ), and in the 1997 Council of Europe Oviedo Convention on Human Rights and Biomedicine (available from http://www.coe.int ).

4. The first figure is found in the House of Commons Science and Technology Select Committee (2001) report on genetics and insurance; the second can be found in A. S. Macdonald (1997), p. 1069. See, also, T. S. Leigh (1990). Le Grys (1997) gives a figure of "up to 95\%."

5. For a presentation of the contrast between mutuality and solidarity by a practising consultant actuary, see Wilkie (1997). On the economics of insurance systems, see Barr (2004), ch. 5.

6. Notwithstanding worries about regional variation and the so-called "postcode lottery," whereby healthcare cover arbitrarily depends on regional variations in resourceallocation and health policy.

7. On the characterisation of "adverse selection" (or "anti-selection"), see, for example, Macdonald (1997) and Wilkie (1997). On the economics of adverse selection and moral hazard, see Barr (2004), and also Akerlof (1970), Pauly (1974), and Stiglitz (1983).

8. I am grateful to Onora O'Neill for this point.

9. On the principle of "utmost good faith," the characterisation of insurance contracts as uberrima fidei, and the duty of disclosure that this involves, see Lowry and Rawlings (2005), ch. 4, and Birds and Hird (2004), pp. 105-21. The doctrine of insurance contracts as involving "utmost good faith" in English law goes back to the verdict of Lord Mansfield in Carter vs. Boehm (1766) 3 Burr 1905. As Mansfield puts it, "Insurance is a contract of speculation. The special facts upon which the contingent chance is to be computed lie most commonly in the knowledge of the assured [i.e., the insuree] only; the underwriter trusts to his representation, and proceeds upon confidence that he does not keep back any circumstance in his knowledge to mislead the underwriter into a belief that the circumstance does not exist. ... Good faith forbids either party, by concealing what he privately knows, to draw the other into a bargain from his ignorance of the fact, and his believing the contrary." To the extent that modern commercial insurers demand uberrima fides, but do not always offer it (e.g., by withholding information on the insuree, on the basis of which actuarial judgements are made) we have the emergence of a separate, but pressing, legal and ethical problem.

10. On these structural features of mutual insurance contracts, see Wilkie (1997), and Barr (2004).

11. Bell (1997), p. 1051.

12. It is worth bearing in mind that the existence of tests for early-onset genetic conditions are still of great significance for access to health insurance, in systems where such access is organized through a mutual insurance market.

13. See Harper (1997), and Bell (1997).

14. On plausible advances in genetic medicine, see Anderson (1997). In the U.K., a massive recent investment has been made in studying the interplay of lifestyle, environment, and genetics with regard to such conditions. See, for example, the U.K. Biobank website at: http://www.ukbiobank.ac.uk. Such a "biobank" scheme is also currently underway in Japan.

15. On optimistic and pessimistic responses to recent genetic advances, see Macintyre (1997).

16. For the current "Concordat and Moratorium on Genetics and Insurance," see Department of Health (2005a). For GAIC's previous reports, see Department of Health (2000) 
through (2005b). For other elements of U.K. political deliberation on this matter, see the report of the House of Commons Select Committee on Science and Technology (2001), and the publications of the Human Genetics Commission, especially (2002) and (2005).

17. See Rawls (1971), §12.

18. Indeed, a general principle regarding the impermissibility of genetic discrimination seems to be emerging in a number of jurisdictions-for example, in the 2005 U.S. "Genetic Information Non-Discrimination Act." Also of relevance here is the 1997 UNESCO "Universal Declaration on the Human Genome and Human Rights," Article 6 of which asserts that "No one shall be subjected to discrimination based on genetic characteristics that is intended to infringe or has the effect of infringing human rights, fundamental freedoms, and human dignity." [My italics] Also of considerable relevance to our discussion is Article 12 of the Declaration, which states that "Benefits from advances in biology, genetics, and medicine, concerning the human genome, shall be made available to all, with due regard for the dignity and human rights of each individual."

19. Although this plausibly explains why people are not especially exercised by gender discrimination in the pricing of life insurance, it does not show that there is genuinely no principled issue of injustice here.

20. Problems may arise insofar as many smokers are undoubtedly addicted to their smoking habits, may have become addicted under conditions of inadequate information as to the health risks of smoking, and may now continue as smokers despite the fact that they would choose to refrain from smoking if they were genuinely capable of following such a course of action.

21. Thus, Article 16 of the United Nations' Universal Declaration of Human Rights asserts that "The family is the natural and fundamental group unit of society and is entitled to protection by society and the State." See United Nations, (1948).

22. On the sense of "basic structure" that I am employing here, by which I mean to refer to the principal economic and social arrangements of a society, see Rawls (1971), § 2; and Rawls (2001), §§ 3-4.

23. On the Rawlsian idea of "fair equality of opportunity," see his (2001), § 13.

24. Stepping beyond Bill's preference for blissful ignorance, one could also appeal to various versions of the claim that we have a right to an "open future" or a right to certain kinds of ignorance. See, for example, Jonas (1974), and Feinberg (1980). There is also the thought that, as Slavoj Žižek puts it (2003), "if we are to retain our moral dignity, it's better not to know certain things." So, whilst adopting Option 2 might seem to involve taking the approach of the "genetic Luddite," this would be too harsh a judgement given the legitimate concerns that might motivate such a choice. Nevertheless, it seems to me that, whatever the merits of these lines of argument, they get their force only in circumstances where someone like Bill would be denied any choice about whether they were to receive the relevant genetic information.

25. A solidaristic scheme could also be envisaged that replaced only a certain part of the current mutualistic arrangements, given that it might be possible to run a basic solidaristic scheme alongside an open market for those wanting to purchase especially large policies. Nevertheless, such a hybrid scheme would still raise significant problems of social justice.

26. See, for example, Dworkin's presentation of his "equality of resources" view in his (2000), alongside other advocates of choice-sensitive egalitarianism (or 'luck-egalitarianism') such as Cohen (1989), and Arneson (1989). For criticism of choice-sensitive egalitarianism, see, for example, Anderson (1999), and Scheffler (2003) and (2005). For a choicesensitive egalitarian response, see Arneson (2000). 
27. Where the loci classici of the recent debates are, on egalitarianism and/or prioritarianism, Nagel (1977), Parfit (1995), Scanlon (1997), and Temkin (2000); and, on egalitarianism and sufficientarianism, Raz (1986) and Frankfurt (1987). For a general discussion of the range of relevant issues, see Clayton and Williams (2000).

28. On Rawls's idea of the possibility of an "overlapping consensus," see his (1993) Lecture IV. I mean only to borrow Rawls's terminology here for my own purposes; the idea I have in mind is rather less precise than that of Rawls.

\section{REFERENCES}

Aiken, William, and Hugh La Follette, 1980. Whose Child? Children's Rights, Parental Autonomy, and State Power, Totowa, NJ: Rowman and Littlefield.

Akerlof, George A., 1970. "The Market for 'Lemons': Qualitative Uncertainty and the Market Mechanism," Quarterly Journal of Economics, 84, 488-500, reprinted in Barr (ed.) 2001 , i. $308-20$.

Anderson, Elizabeth, 1999. "What is the Point of Equality?," Ethics, 109; 287-337.

Anderson, R. M., 1997. "Conclusions: Scientific Research and its Implications," Philosophical Transactions of the Royal Society of London, B, 352, 1067-75.

Ameson, Richard J., 1989. "Equality and Equality of Opportunity for Welfare," Philosophical Studies, 56: 77-93.

Arneson, Richard J., 2000. "Luck Egalitarianism and Prioritarianism," Ethics, 110, 339-49.

Barr, Nicholas, (ed.), 2001. Economic Theory and the Welfare State, Cheltenham and Northampton, MA: Edward Elgar.

Barr, Nicholas, 2004. The Economics of the Welfare State, 4th ed'n., Oxford: Oxford University Press.

Bell, John, 1997. "Genetics of Common Disease: The Implications for Therapy, Screening and Redefinition of Disease," Philosophical Transactions of the Royal Society of London, B, 352, 1051-55.

Birds, John, and Norma J. Hird, 2004. Birds' Modern Insurance Law, London: Sweet \& Maxwell.

Bodmer, Walter F., 1997. "Genetic Diversity and Disease Susceptibility," Transactions of the Royal Society of London, B, 352, 1045-50.

Buchanan, Allen, and Dan W. Brock, Norman Daniels, and Daniel Wikler, 2000. From Chance to Choice: Genetics and Justice. Cambridge: Cambridge University Press.

Burley, Justine, (ed.), 1999. The Genetic Revolution and Human Rights, Oxford: Oxford University Press.

1999. "Bad Genetic Luck and Health Insurance," in her (ed.), 1999, 54-60.

Burley, Justine and John Harris, (eds.), 2002. A Companion to Genethics, Oxford: Blackwell.

Clayton, Matthew and Andrew Williams, (eds.), 2000. The Ideal of Equality, Basingstoke: Palgrave Macmillan.

2000. "Some Questions for Egalitarians," in their (eds.), 2000, 1-20.

Cohen, G. A., 1989. "On the Currency of Egalitarian Justice," Ethics, 99: 906-44.

Council of Europe, 1997. Convention on Human Rights and Biomedicine, (The Oviedo Convention), agreed at Oviedo, Spain, April 4, 1997. Available online from http://www.coe.it/ 
Daniels, Norman, 2004. "The Functions of Insurance and the Fairness of Genetic Underwriting," in Rothstein, (ed.), 2004, 119-46.

Department of Health (U.K.), 2003. Our Inheritance, Our Future; Realising the Potential of Genetics in the NHS, London: Her Majesty's Stationery Office. Available online at: http://www.dh.gov.uk/PublicationsandStatistics/

Department of Health (U.K.), 2000. Genetics and Insurance Committee (GAIC), 2000. Genetics and Insurance Committee: First Report, London: HMSO.

, 2001. Government Response to the Report of the House of Commons Science and Technology Committee, London: HMSO.

2004. Genetics and Insurance Committee: Second Report, London: HMSO.

, 2005a. Concordat and Moratorium on Genetics and Insurance, London: HMSO.

2005b. Genetics and Insurance Committee: Third Report, London: HMSO.

All of the above publications are available online at:

http://www.advisorybodies.doh.gov.uk/genetics/gaic/

Dworkin, Ronald, 2000. Sovereign Virtue: The Theory and Practice of Equality, Cambridge, MA: Harvard University Press.

Feinberg, Joel, 1980. "The Child's Right to an Open Future," in Aiken and LaFollette, (eds.), 1980.

Frankfurt, Harry, 1987. "Equality as a Moral Ideal," Ethics, 98: 1, 21-43, reprinted in his $1988,134-58$.

, 1988. The Importance of What We Care About, Cambridge: Cambridge University Press.

Harper, P. S., 1997. “Genetic Testing, Life Insurance and Adverse Selection," Philosophical Transactions of the Royal Society of London, B, 352, 1063-65.

House of Commons (U.K.), 2001. Fifth Report of the Select Committee on Science and Technology: On Genetics and Insurance. Available online at http://www.parliament.uk/

Hudson, Kathy L., et al., 1995. "Genetic Discrimination and Health Insurance: An Urgent Need for Reform," Science, 270, 391-93.

Human Genetics Commission (HGC) (U.K.), 2002. Inside Information: Balancing Interests in the Use of Personal Genetic Data.

, 2005. "Support for Moratorium on Genetics and Insurance," Press Release, 14 March 2005. Both available online at: http://www.hgc.gov.uk/

Jonas, Hans, 1974. Philosophical Essays: From Ancient Creed to Technological Man, Englewood Cliffs, NJ: Prentice Hall.

Knoppers, Bartha Maria, 1999. "Who Should Have Access to Genetic Information?," in Burley (ed.), 39-53.

Le Grys, D. J., 1997. "Actuarial Considerations on Genetic Testing," Transactions of the Royal Society of London, B, 352, 1057-61.

Leigh, T. S., 1990. "Underwriting: A Dying Art?," Journal of the Institute of Actuaries, 117: 443-531.

Lowry, John P. and Philip Rawlings, 2005. Insurance Law: Doctrines and Principles, 2nd ed'n. Oxford: Hart.

Macdonald, Angus, 1997. "How Will Improved Forecasts of Individual Lifetimes Affect Underwriting?," Philosophical Transactions of the Royal Society of London, B, 352, 1067-75.

Macintyre, Sally, 1997. "Social and Psychological Issues Associated with the New Genetics," Philosophical Transactions of the Royal Society of London, B, 352, 1095-1101. 
Nagel, Thomas, 1977. "Equality," delivered as the Tanner Lecture at Stanford University, and available online at http://www.tannerlectures.utah.edu. Reprinted in Clayton and Williams, (eds.), 2000, 60-80.

National Human Genome Research Institute (U.S.), 2005. Information relating to the "Genetic Discrimination in Health Insurance and Employment Act," available from http://www.genome.gov/

O'Neill, Onora, 1997. "Genetic Information and Insurance: Some Ethical Issues," Philosophical Transactions of the Royal Society of London, B, 352, 1087-93.

1998. "Genetics, Insurance and Discrimination," Transactions of the Manchester Statistical Society, 1-14.

Parfit, Derek, 1995. "Equality or Priority?" given as the Lindley Lecture at the University of Kansas, and reprinted in Clayton and Williams (eds.), 2000, 81-125.

Pauly, Mark V., 1974. "Overinsurance and Public Provision of Insurance: The Roles of Moral Hazard and Adverse Selection," Quarterly Journal of Economics, 88: 44-62, reprinted in Barr (ed.) 2001, i. 321-39.

Radetzki, Marcus, Marian Radetzki, and Niklas Juth, 2003. Genes and Insurance: Ethical, Legal and Economic Issues, Cambridge: Cambridge University Press.

Rawls, John, 1971. A Theory of Justice, Cambridge, MA: Harvard University Press. 1993. Political Liberalism, Cambridge, MA: Harvard University Press. , 2001. Justice as Fairness: A Restatement, Cambridge, MA: Harvard University Press.

Raz, Joseph, 1986. The Morality of Freedom, Oxford: Clarendon Press.

Rothstein, Mark A., (ed.), 2004. Genetics and Life Insurance: Medical Underwriting and Social Policy, Cambridge, MA: M.I.T. Press.

Scanlon, T. M., 1997. "The Diversity of Objections to Inequality," delivered as the Lindley Lecture at the University of Kansas, and reprinted in Clayton Williams (eds.) 2000, 41-59.

Scheffler, Samuel, 2003. "What Is Egalitarianism?," Philosophy and Public Affairs, 31:1, 5-39. 2005. "Choice, Circumstance, and the Value of Equality," Politics, Philosophy and Economics, 4:1, 5-28.

Sorell, Tom, 2002. "The Insurance Market and Discriminatory Practices," in Burley and Harris, (eds.), 398-407.

Stiglitz, Joseph E., 1983. "Risk, Incentives and Insurance: The Pure Theory of Moral Hazard," Geneva Papers on Risk and Insurance, 8:26, 4-33, reprinted in Barr (ed.), 2001 , i. 361-90.

Temkin, Larry, 2000. "Equality, Priority and the Levelling Down Objection," in Clayton and Williams, (eds.), 2000, 126-61.

U.K. Biobank, Information available online at: http://www.ukbiobank.ac.uk

United Nations, 1948. Universal Declaration of Human Rights. Available online at: http://www.unhchr.ch/udhr/index.htm

UNESCO, 1997. Declaration on the Human Genome and Human Rights. Available online from: http://www.unesco.org

Wilkie, David, 1997. "Mutuality and Solidarity: Assessing Risks and Sharing Losses," Philosophical Transactions of the Royal Society of London, B, 352, 1039-44.

Žižek, Slavoj, 2003. "Bring Me My Phillips Mental Jacket," London Review of Books, 25:10. 
Copyright of Monist is the property of Hegeler Institute and its content may not be copied or emailed to multiple sites or posted to a listserv without the copyright holder's express written permission. However, users may print, download, or email articles for individual use. 